\title{
ИНТЕГРАЦИОННЫЙ АНАЛИЗ ВНЕШНЕЙ СРЕДЫ И ВНУТРЕННЕГО ПОТЕНЦИАЛА ПРЕДПРИЯТИЯ
}

В статье поставлена цель на основании интеграционного анализа внеиней среды и внутреннего потенциала предприятия выработать ряд целеустановок, которые могут стать базисом для формирования и последующей реализации рыночной стратегии компании. В рамках исследования решена задача выявления теоретических основ и практической применимости наиболее популярных, таких как модель Майкла Портера и SNW-анализ, при формировании стратегии развития предприятия. Исследование позволило как определить ряд иелесустановок, среди которых иели; показатели, которые следует вычислять при оценке и контроле прочесса реализаци стратегии, и их иелевые значения, так и предложить комплекс инициатив, даюиих возножность поэтапной корректировки стратегии в прочессе ее реализации.

Ключевые слова: интеграционный анализ, внешняя среда, внутренний потенциал, стратегия, уелеустановки.

\section{Ellina Depershmidt \\ INTEGRATION ANALYSIS OF THE ENTERPRISE'S EXTERNAL ENVIRONMENT AND INTERNAL CAPACITY}

The article sets as the goal on the basis of the integration analysis of the external environment and the internal capacity of the enterprise to develop a number of targets that can serve as the basis for the formation and subsequent implementation of the company's market strategy. Within the framework of the research, it was solved the task to determine the theoretical foundations and practical applicability of the most popular approaches, including the model of Michael Porter and SNW analysis, during the formation of an enterprise development strategy. The study has given a possibility to identify a number of targets, among which goals, indicators that are to be calculated when evaluating and monitoring the process of implementing a strategy, and their target values, to offer a set of initiatives enabling a phased adjustment of the strategy during its implementation.

Key words: integration analysis, external environment, internal capacity, strategy, goal setting.

Bведение /Introduction. В условиях усиливающегося влияния рисков и различных факторов внешней среды на внутренний потенциал предприятия повышается актуальность проблематики разработки наиболее эффективного или оптимального инструментария для реализации стратегии развития отдельно взятых компаний в неравновесной и нестабильной конкурентной среде.

Анализ научных исследований позволяет выявить повышенный интерес современных ученых к проблемам формирования рыночной стратегии предприятия с целью наиболее полной реализации его внутреннего потенциала. Так, О. Баженов [1] предлагает методику формирования прогнозных данных на основе результатов стратегического анализа (на примере предприятий медной промышленности), Т. Дивина [2] анализирует ряд принципов построения антикризисных программ в контексте современной экономической ситуации, В. Калышенко и У. Сталькина [3] проводят стратегический анализ маркетинговой среды предприятия, К. Скворцова [4] исследует процесс развития методики оценки уровня экономической безопасности предприятия, А. Тарелкин [5] разрабатывает алгоритм оценки инвестиционной привлекательности промышленных предприятий. 
Тем не менее актуальными остаются вопросы выработки стратегии для каждого конкретного предприятия на основании анализа факторов внешней и внутренней среды и силы их воздействия на экономическую эффективность и результативность субъекта хозяйственно-экономической деятельности.

Именно эта предпосылка дала возможность сформулировать цель данной статьи, которая заключается в следуюшем: на основании интеграционного анализа внешней среды и внутреннего потенциала предприятия выработать ряд целеустановок, которые могут стать базисом для формирования и последующей реализации рыночной стратегии компании в среднесрочной перспективе (предлагаемое исследование осуществляется на примере ООО «Завод Гнутого Профиля»).

Достижение поставленной цели потребовало решения задачи исследования теоретических основ, обоснования и выработки рекомендаций относительно практической применимости существующих наиболее популярных и часто используемых подходов, среди которых модель Майкла Портера и SNW-анализ, при формировании стратегии развития предприятия.

Maтериалы и методы / Materials and methods. При проведении исследования были применены различные модели определения рыночных позиций предприятия, среди которых наиболее популярные модель Майкла Портера и SNW-анализ. При научном анализе использовались результаты изысканий, представленные в монографиях, научных и методических публикациях, аналитических докладах, статистических справочниках, отчетность предприятия и материалы законодательных актов и правоустанавливающих документов.

Результаты и обсуждение / Results and discussion. Предлагаемый анализ целесообразно сформировать путем рассмотрения различных теоретических моделей и определения их применимости к выбранному предприятию с двух позиций: анализ существующего положения компании и определение стратегических векторов дальнейшего развития.

Исследование первой позиции предлагается проводить в рамках двух наиболее популярных моделей [6]: модель Майкла Портера и SNW-анализ.

1. Модель Майкла Портера (анализ пяти сил конкуренции). Стратегическая модель анализа пяти сил конкуренции, разработанная М. Портером в 1979 г., включает исследование структурных составляющих, присущих каждой отрасли. Модель предлагает разработку стратегии, основной целью которой является адаптация фирмы к конкурентной рыночной среде, базируясь на методах формирования конкурентного преимущества, что приводит к длительному удержанию прибыльности продаваемого продукта и помогает сохранять конкурентоспособность компании в долгосрочной перспективе.

В соответствии с теорией М. Портера, возможный уровень прибыли любого предприятия в условиях нестабильной конкурентной среды определяется под воздействием пяти движущих сил, характеризующих степень конкурентоспособности продаваемого продукта, соответственно: угроза вторжения новых игроков, рыночная власть, с одной стороны, покупателей и, с другой - поставщиков, риск появления товаров-заменителей, уровень рыночной и внутриотраслевой конкуренции. Именно описанные составляющие считаются движущими силами конкуренции на рынке.

Анализ в рамках модели Портера дает возможность выявить интенсивность влияния конкурентных сил, определить такую позицию, где фирма будет находиться под минимальным воздействием конкурентных сил и одновременно адекватно реагировать и оказывать влияние на них.

Золотое правило модели пяти факторов гласит, что количество и качество возможностей предприятия повышать прибыль в рамках отрасли обратно пропорционально воздействию сил конкуренции. Кроме того, средняя прибыльность компаний внутри отрасли варьируется в зависимости от воздействия наиболее значительных конкурентных сил, каждую из которых кратко рассмотрим ниже. 
Угроза появления новых игроков предполагает, что выход новых участников привносит новаторские ресурсные и производственные факторы, что может вызвать потрясения в отрасли и трансформировать поведение потребителей, изменить стандарты функционирования для действующих игроков. Однако в соответствии с законом самосохранения каждая отрасль формирует своеобразные входные барьеры, сила влияния которых, по мнению Портера, обусловливается соответствующими ключевыми факторами: экономия на масштабе; дифференциация или диверсификация продукта и сила представленных на рынке торговых марок; потребность в стартовом капитале; величина постоянных издержек; доступность каналов сбыта и распределения, свидетельствующая о легкости достижения целевой аудитории; политика правительства, направленная на создание накладываемых государством ограничений функционирования отрасли; дополнительные угрозы, связанные с наличием у функционирующих игроков, с одной стороны, резервного потенциала для активного противостояния и противодействия входу новых участников рынка и, с другой стороны, объективных факторов рыночной среды.

Рыночная власть (PB). РВ покупателей предполагает, что, разрабатывая стратегию, фирма должна ориентироваться на аудиторию менее влиятельных покупателей с точки зрения их участия в конкуренции посредством удовлетворения потребностей и создания спроса на готовый товар. При этом условия влияния покупателей на уровень конкуренции могут быть описаны следующим образом:

- $\quad$ высокая степень концентрации покупателей и масштабность закупок ими товаров, что вызывает необходимость у производителей идти на уступки для обеспечения гарантированного дохода;

- $\quad$ наличие широкого ассортимента товаров-аналогов или субститутов;

- $\quad$ высокая чувствительность покупателей к цене и потребность в снижении будущих затрат;

- $\quad$ готовый продукт потребляется в качестве сырья для дальнейшего производства, при этом покупатели склонны к снижению издержек и поиску альтернативных поставщиков на более выгодных ценовых условиях;

- $\quad$ неудовлетворенность покупателей качеством предлагаемых товаров и сопутствующим сервисом.

РВ поставщиков реализуется на рынке, оказывая воздействие на конкурентоспособность услуги или товара, посредством перераспределения ресурсов с последующим влиянием на себестоимость товара и издержки производства и далее на общую прибыльность предприятия в следующих четырех ситуациях: в условиях монополии и олигополии при малом количестве поставщиков; при крайне ограниченном объеме ресурсов; при уникальности ресурсов; при неприоритетности отрасли и, соответственно, более высокой доходности реализации ресурсов вне отрасли.

Bыход на рынок товаров-субститутов приводит к снижению верхних ценовых границ и, как следствие, к сокращению доходов компании. Наиболее опасными представляются товары-заменители, предлагающие лучшее соотношение цены и качества; производимые крупными игроками, для которых данный рынок не является приоритетным.

Однако появление субститутов стимулирует существующих игроков к укреплению торговой марки и построению рыночной стратегии, направленной на повышение покупательской лояльности.

Внутриотраслевая конкуренция представляется борьбой за лидирующие позиции на рынке, приводя, с одной стороны, к ценовой конкуренции, а с другой - к повышению затрат на продвижение и улучшение товара и последующему снижению прибыльности. Рост уровня конкуренции наблюдается в следующих условиях: наличие большого количества равнозначных по объемам продаж игроков; высокая стандартизация товара, приводящая к низкой лояльности потребителя одному производителю; продукт является скоропортящимся; высокие затраты на выход из отрасли формируют низкорентабельных игроков и избыток мощностей производства. 
Если представить «Анализ пяти сил Портера» в пространственном виде, то можно выявить три силы «горизонтальной» конкуренции: угроза появления продуктов-заменителей, угроза появления новых игроков, уровень конкурентной борьбы; и две силы «вертикальной» конкуренции: рыночная власть поставщиков и рыночная власть потребителей. Для выхода на лидирующие позиции среди конкурентов (пять конкурентных сил), по результатам анализа, предприятие разрабатывает стратегию, ограждаюшую от угроз конкурентных сил, обеспечивает долгосрочную конкурентоспособность предприятия и прибыльную деятельность.

Из анализа таблицы 1 видно, что для предприятия ООО «Завод гнутого профиля» основные угрозы исходят от поставщиков сырья.

Таблица 1

\section{Анализ конкурентных сил ООО «Завод гнутого профиля»}

\begin{tabular}{|c|c|c|c|}
\hline \multicolumn{4}{|c|}{ Оценка параметра в баллах } \\
\hline \multicolumn{4}{|c|}{ 1.Угроза со стороны товаров-субститутов } \\
\hline \multirow{2}{*}{$\begin{array}{c}\text { Товары (субституты), ко- } \\
\text { торые имеют аналогичные } \\
\text { качественные и целевые } \\
\text { характеристики }\end{array}$} & Не выявлены & $\begin{array}{c}\text { Незначительная доля } \\
\text { рьнка, поскольку } \\
\text { недавно на рьнке }\end{array}$ & $\begin{array}{c}\text { Давно на рынке } \\
\text { с большой его долей }\end{array}$ \\
\hline & & 2 & \\
\hline $\begin{array}{c}\text { Итог в баллах } \\
\text { (качественная оценка) }\end{array}$ & \multicolumn{3}{|c|}{2 (уровень угрозы средний) } \\
\hline \multicolumn{4}{|c|}{ 2. Оценка угрозы внутриотраслевой конкуренции } \\
\hline \multirow[t]{2}{*}{ Число участников } & $\begin{array}{c}1-3 \text { балла } \\
\text { (низкий уровень) }\end{array}$ & $\begin{array}{c}\text { 3-10 баллов } \\
\text { (средний уровень) }\end{array}$ & $\geq 10$ (высокий уровень) \\
\hline & 1 & & \\
\hline \multirow[t]{2}{*}{$\begin{array}{l}\text { Уровень дифференциации } \\
\text { товара среди конкурентов }\end{array}$} & $\begin{array}{c}\text { Значительная степень } \\
\text { отличия друг от друга } \\
\text { товаров разных } \\
\text { производителе }\end{array}$ & $\begin{array}{c}\text { Относительно } \\
\text { стандартный товар, } \\
\text { но с определенными } \\
\text { преимуществами }\end{array}$ & $\begin{array}{c}\text { Стандартный для всех } \\
\text { предприятий-производи- } \\
\text { телей товар }\end{array}$ \\
\hline & 1 & & \\
\hline \multirow{2}{*}{$\begin{array}{c}\text { Темпы расширения } \\
\text { доли рынка }\end{array}$} & Высокий темп & Средний темп & $\begin{array}{c}\text { Стандартизация } \\
\text { доли рынка }\end{array}$ \\
\hline & & 2 & \\
\hline \multirow[t]{2}{*}{$\begin{array}{c}\text { Ограничения, } \\
\text { накладываемые условиями } \\
\text { рынка, на рост цен }\end{array}$} & $\begin{array}{c}\text { Нежесткая конкурентная } \\
\text { ценовая борьбы, позво- } \\
\text { ляющая поднимать цену } \\
\text { для увеличения прибыли } \\
\text { и покрытия затрат } \\
\end{array}$ & $\begin{array}{c}\text { Затраты растут, но есть } \\
\text { возможность поднятия } \\
\text { цен для покрытия затрат }\end{array}$ & $\begin{array}{c}\text { Высокий уровень кон- } \\
\text { куренции по цене, что } \\
\text { делает невозможным } \\
\text { повышение цен }\end{array}$ \\
\hline & 1 & & \\
\hline $\begin{array}{c}\text { Итог в баллах } \\
\text { (качественная оценка) }\end{array}$ & \multicolumn{3}{|c|}{5 баллов (уровень угрозы - средний) } \\
\hline \multicolumn{4}{|c|}{ 3. Угроза возможности появления новых игроков на рынке } \\
\hline \multirow{2}{*}{$\begin{array}{c}\text { Экономия } \\
\text { на эффекте масштаба }\end{array}$} & Выявлена & $\begin{array}{c}\text { Выявлена у некоторых } \\
\text { участников }\end{array}$ & Не выявлена \\
\hline & 1 & & \\
\hline \multirow{2}{*}{$\begin{array}{l}\text { Присутствие крупных } \\
\text { игроков на рынке }\end{array}$} & $\begin{array}{c}80 \% \text {-я доля занята } 2 / 3 \\
\text { крупных игроков }\end{array}$ & $\begin{array}{c}50 \text { \%-я доля занята } 2 / 3 \\
\text { крупных игроков } \\
\end{array}$ & $\begin{array}{c}\text { На рынке не присутству- } \\
\text { ют крупные игроки }\end{array}$ \\
\hline & 1 & & \\
\hline
\end{tabular}




\begin{tabular}{|c|c|c|c|}
\hline \multirow{3}{*}{$\begin{array}{c}\text { Анализируемый параметр } \\
\text { Степень дифференциации } \\
\text { товара }\end{array}$} & \multicolumn{3}{|c|}{ Оценка параметра в баллах } \\
\hline & $\begin{array}{c}\text { Все ниши заняты участ- } \\
\text { никами }\end{array}$ & $\begin{array}{c}\text { Наличие свободных } \\
\text { микрониш }\end{array}$ & $\begin{array}{c}\text { Товар не диверсифици- } \\
\text { рован }\end{array}$ \\
\hline & & 2 & \\
\hline \multirow{2}{*}{$\begin{array}{c}\text { Объем затрат на вход на } \\
\text { отраслевой рынок и сроки } \\
\text { их окупаемости }\end{array}$} & $\begin{array}{c}\text { Более } 19 \text { месяцев (дол- } \\
\text { госрочная окупаемость) }\end{array}$ & $\begin{array}{c}\text { От } 6 \text { до } 19 \text { месяцев } \\
\text { (среднесрочная окупае- } \\
\text { мость) }\end{array}$ & $\begin{array}{c}\text { От } 1 \text { до } 3 \text { месяцев } \\
\text { (краткосрочная окупае- } \\
\text { мость) }\end{array}$ \\
\hline & & 2 & \\
\hline \multirow[t]{2}{*}{ Доступ к капиталам } & Ограниченный & $\begin{array}{c}\text { Потребность в умерен- } \\
\text { ных капиталовложениях }\end{array}$ & Открытый \\
\hline & & 2 & \\
\hline \multirow[t]{2}{*}{ Госполитика } & $\begin{array}{c}\text { Полный контроль над } \\
\text { отраслью со стороны } \\
\text { государства }\end{array}$ & $\begin{array}{l}\text { Слабый контроль над } \\
\text { отраслью со стороны } \\
\text { государства }\end{array}$ & $\begin{array}{c}\text { Отсутствие контроля } \\
\text { над отраслью со сторо- } \\
\text { ны государства }\end{array}$ \\
\hline & & & 1 \\
\hline \multirow{2}{*}{$\begin{array}{c}\text { Темпы развития и роста } \\
\text { отрасли }\end{array}$} & $\begin{array}{c}\text { Стагнация или низкий } \\
\text { темп } \\
\end{array}$ & Средний темп & Значительный темп \\
\hline & & 2 & \\
\hline \multirow{2}{*}{$\begin{array}{c}\text { Готовность участников } \\
\text { к понижению цены }\end{array}$} & $\begin{array}{c}\text { Участники готовы сни- } \\
\text { жать цены }\end{array}$ & $\begin{array}{c}\text { Крупные участники не } \\
\text { готовы снижать цены }\end{array}$ & $\begin{array}{c}\text { Участники не снижают } \\
\text { цены }\end{array}$ \\
\hline & & & 1 \\
\hline $\begin{array}{c}\text { Итог в баллах } \\
\text { (качественная оценка) }\end{array}$ & \multicolumn{3}{|c|}{11 баллов (уровень угрозы - средний) } \\
\hline \multicolumn{4}{|c|}{ 4. Оценка угрозы ухода потребителей } \\
\hline \multirow[t]{2}{*}{$\begin{array}{c}\text { Кол-во потребителей с } \\
\text { большим объемом покупок }\end{array}$} & $\begin{array}{l}\text { Равномерное распреде- } \\
\text { ление объема потребле- } \\
\text { ния }\end{array}$ & $\begin{array}{c}50 \% \text { продаж обеспечены } \\
\text { небольшой долей потре- } \\
\text { бителей }\end{array}$ & $\begin{array}{c}80 \% \text { покупок обеспече- } \\
\text { ны несколькими потре- } \\
\text { бителями }\end{array}$ \\
\hline & & 2 & \\
\hline \multirow{2}{*}{$\begin{array}{c}\text { Вероятность ухода } \\
\text { потребителя к другому } \\
\text { производителю }\end{array}$} & $\begin{array}{c}\text { Безаналоговый уникаль- } \\
\text { ный продукт }\end{array}$ & $\begin{array}{c}\text { Стандартный продукт с } \\
\text { отличительными харак- } \\
\text { теристиками }\end{array}$ & $\begin{array}{c}\text { Стандартный продукт, } \\
\text { наличие товаров-субсти- } \\
\text { тутов }\end{array}$ \\
\hline & 1 & & \\
\hline \multirow[t]{2}{*}{$\begin{array}{c}\text { Ценовая чувствительность } \\
\text { покупателя к цене }\end{array}$} & $\begin{array}{l}\text { Нулевая или низкая } \\
\text { чувствительность }\end{array}$ & $\begin{array}{c}\text { Средняя чувствитель- } \\
\text { ность }\end{array}$ & $\begin{array}{c}\text { Переключается на } \\
\text { продукт более низкой } \\
\text { ценовой категории }\end{array}$ \\
\hline & & 2 & \\
\hline \multirow[t]{2}{*}{$\begin{array}{c}\text { Степень удовлетворенности } \\
\text { качеством товара }\end{array}$} & $\begin{array}{c}\text { Полная удовлетворен- } \\
\text { ность }\end{array}$ & $\begin{array}{c}\text { Неудовлетворенность } \\
\text { дополнительными } \\
\text { х-ками }\end{array}$ & $\begin{array}{l}\text { Неудовлетворенность } \\
\text { основными х-ками }\end{array}$ \\
\hline & 1 & & \\
\hline $\begin{array}{c}\text { Итог в баллах } \\
\text { (качественная оценка) }\end{array}$ & \multicolumn{3}{|c|}{6 баллов (уровень угрозы - средний) } \\
\hline \multicolumn{4}{|c|}{ 5. Оценка угрозы со стороны поставщиков } \\
\hline \multirow{2}{*}{$\begin{array}{c}\text { Количество производителей } \\
\text { и поставщиков }\end{array}$} & Большое & Лимитированное & \\
\hline & & 3 & \\
\hline \multirow{2}{*}{$\begin{array}{l}\text { Издержки или стоимость } \\
\text { смены поставщика сырья }\end{array}$} & Низкие & Высокие & \\
\hline & & 2 & \\
\hline
\end{tabular}




\begin{tabular}{|c|c|c|c|}
\hline Анализируемый параметр & \multicolumn{3}{|c|}{ Оценка параметра в баллах } \\
\hline \multirow{2}{*}{$\begin{array}{c}\text { Ограниченность объема } \\
\text { поставок }\end{array}$} & $\begin{array}{l}\text { Не имеющие ограниче- } \\
\text { ний }\end{array}$ & Имеющие ограничения & \\
\hline & & 2 & \\
\hline \multirow{2}{*}{$\begin{array}{l}\text { Степень приоритетности } \\
\text { отрасли для поставщика }\end{array}$} & Высокая & Низкая & \\
\hline & & 2 & \\
\hline $\begin{array}{c}\text { Итог в баллах } \\
\text { (качественная оценка) }\end{array}$ & \multicolumn{3}{|c|}{9 баллов (уровень угрозы - высокий) } \\
\hline
\end{tabular}

* Составлено авторам на основе материалов [6, с. 50-52; 7$]$

Пользуясь своими неоспоримыми преимуществами: оперативность обработки заказа, собственное производство, срок изготовления от 1 дня, широкий перечень гофр, качество выполнения заказов (новичкам на этом рынке часто делают возвраты и расторгают контракты), грамотные специалисты, изготовление длины согласно чертежей, предоставленных заказчиком, поставка сопутствующих товаров (доборных элементов, крепежей), ООО ЗГП осуществляет продажу продукции по максимально возможной цене с целью расширения производства и максимизации прибыли, соответственно и стоимости компании в целом.

2. SNW-анализ. Этот подход представляется вариантом углубленного SWOT-анализа, поскольку предлагает к исследованию, помимо сильных и слабых, и нейтральные стороны (среднерыночное состояние) рыночного положения компании.

$\mathrm{SNW}$-анализ исследуемого предприятия представлен в табл. 2, где буквой «k» отмечена позиция основного конкурента ПА) ЧЗПСН-профнастил.

Таблица 2

SNW-анализ OOO «Завод Гнутого Профиля*

\begin{tabular}{|c|c|c|c|}
\hline \multirow{2}{*}{ Стратегические позиции и характеристики } & \multicolumn{3}{|c|}{ Качественная оценка } \\
\hline & S (сильная) & N (нейтральная) & W (слабая) \\
\hline 1. Общая (корпоративная) стратегия & $\mathrm{K}$ & & $\mathrm{X}$ \\
\hline 2. Бизнес-стратегии по конкретным бизнесам & & k & $\mathrm{X}$ \\
\hline 3. Организационная структура & & $\mathrm{Xk}$ & \\
\hline 4. Финансы как общее финансовое положение & $\mathrm{Xk}$ & & \\
\hline 5. Продукт и его конкурентоспособность & $\mathrm{X}$ & $\mathrm{k}$ & \\
\hline 6. Структура затрат & & $\mathrm{Xk}$ & \\
\hline 7. Информационная технология & & $\mathrm{Xk}$ & \\
\hline 8. Способность к реализации на рынке новых продуктов & & $\mathrm{Xk}$ & \\
\hline 9. Доступ к сырью и материалам & & $\mathrm{Xk}$ & \\
\hline $\begin{array}{l}\text { 10. Соответствие оборудования конкурентным требо- } \\
\text { ваниям }\end{array}$ & $\mathrm{Xk}$ & & \\
\hline 11. Способность к лидерству & $\mathrm{Xk}$ & & \\
\hline 12. Уровень производства & $\mathrm{K}$ & $X$ & \\
\hline 13. Уровень маркетинга & & $\mathrm{Xk}$ & \\
\hline 14. Уровень менеджмента & & $\mathrm{X}$ & $\mathrm{k}$ \\
\hline 15. Качество персонала & & $\mathrm{Xk}$ & \\
\hline 16. Возможность карьерного роста & & $\mathrm{Xk}$ & \\
\hline 17. Мотивация персонала & $\mathrm{X}$ & & $\mathrm{k}$ \\
\hline
\end{tabular}




\begin{tabular}{|c|c|c|c|}
\hline \multirow{2}{*}{ Стратегические позиции и характеристики } & \multicolumn{3}{|c|}{ Качественная оценка } \\
\hline & $\mathrm{S}$ (сильная) & N (нейтральная) & W (слабая) \\
\hline 18. Текучесть персонала & $\mathrm{K}$ & $\mathrm{X}$ & \\
\hline 19. Репутация на рынке & $\mathrm{Xk}$ & & \\
\hline 20. Отношение с органами власти & $\mathrm{Xk}$ & & \\
\hline 21. Инновации и исследования & & $\mathrm{Xk}$ & \\
\hline
\end{tabular}

*Состаелено автораи на основе материалов [7]

Для 000 «ЗГП» анализ в рамках модели SNW представлен на рис. 1.

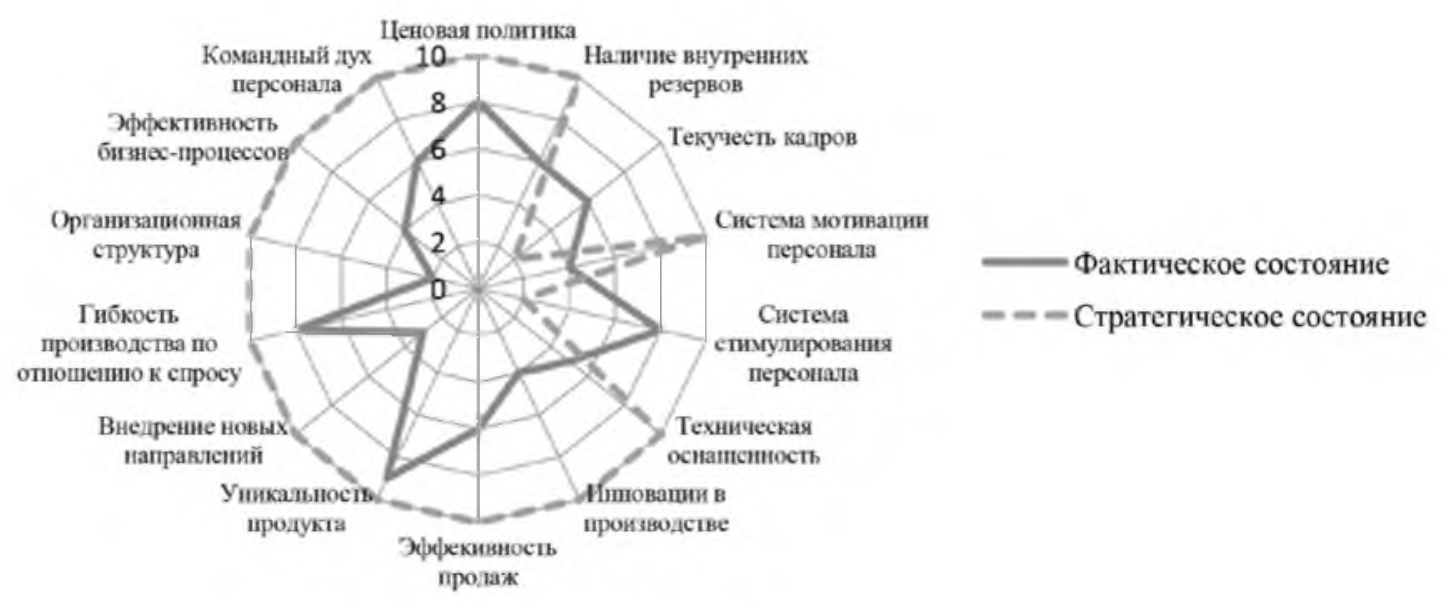

Рис. 1. SNW - анализ внутренней среды ООО «Завод Гнутого Профиля» в 2017 г.*

*Рассчитано и составлено автором на основе материалов [7]

При разработке стратегии рыночного поведения предприятия наиболее эффективными себя зарекомендовали несколько моделей. Их обзор и анализ деятельности ООО «ЗГП» в рамках каждой из рассматриваемых моделей представим далее в нашем исследовании.

1. Модель М. Портера предполагает развитие в направлении трех основных типов стратегии: лидерство по издержкам основывается только на ценовой конкуренции для схожих продуктов; дифференциация предусматривает улучшение или изменение качеств продукта, чтобы сделать его узнаваемым среди конкурентов; фокусирование или концентрация рассчитаны на удовлетворение спроса на изолированном сегменте рынка путем специализации.

В рамках этой концепции ООО «ЗГП» планирует развиваться в направлении стратегии дифференциации и концентрации.

2. Модель И. Ансоффа выстроена на сочетании «продукт - рынок», и стратегия планируется на основании матрицы (рис. 2).

\begin{tabular}{|c|c|c|}
\hline Старын̆ рынок & $\begin{array}{c}\text { Сохранснис } \\
\text { сушсствуюшето } \\
\text { положення, ухоз }\end{array}$ & Развнтис продукта \\
\hline \multirow[t]{2}{*}{ Новый рынок } & Разввитие рынка & Диверсификация \\
\hline & Старнй лродаукт & Нозын продукт \\
\hline
\end{tabular}

Рис. 2. Матрица «продукт - рынок», по Ансоффу 
В рамках работы ООО «Завод Гнутого Профиля» реализуется стратегия развития рынка и стратегия связной и несвязной диверсификации. Это, в свою очередь, предполагает, что развитие рынка осуществляется с точки зрения новой целевой аудитории как нового рынка реализации продукта, а также сотрудничество с отраслями, потребляющими изделия с аналогичной полезностью. Таюже в настоящий момент ООО «ЗГП» разрабатывает стратегию развития в направлении франчайзинговых услуг, что является примером несвязной диверсификации. Связная диверсификация проявляется в изготовлении связных продуктов с существующими при использовании имеющихся мощностей.

3. Модель BCG реализуется на основании матрицы (рис. 3 и рис. 4)

В рамках концепции «Темпы роста доли рынка» (BCG) (рис. 4), если рассматривать все продукты ООО «ЗГП» в качестве портфеля, то часть изделий завода находится в секторе «Дойные коровы», вторая часть «Звезды». На данные момент в процесс производства запущены новые изделия, которые больше напоминают «темных лошадок».

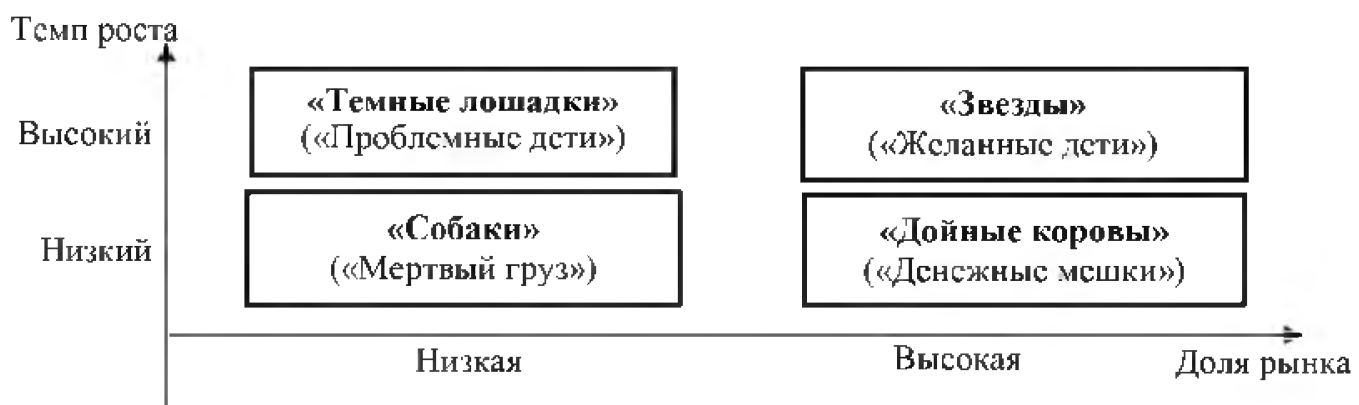

Рис. 3. Модель «Темпы роста доли рынка»

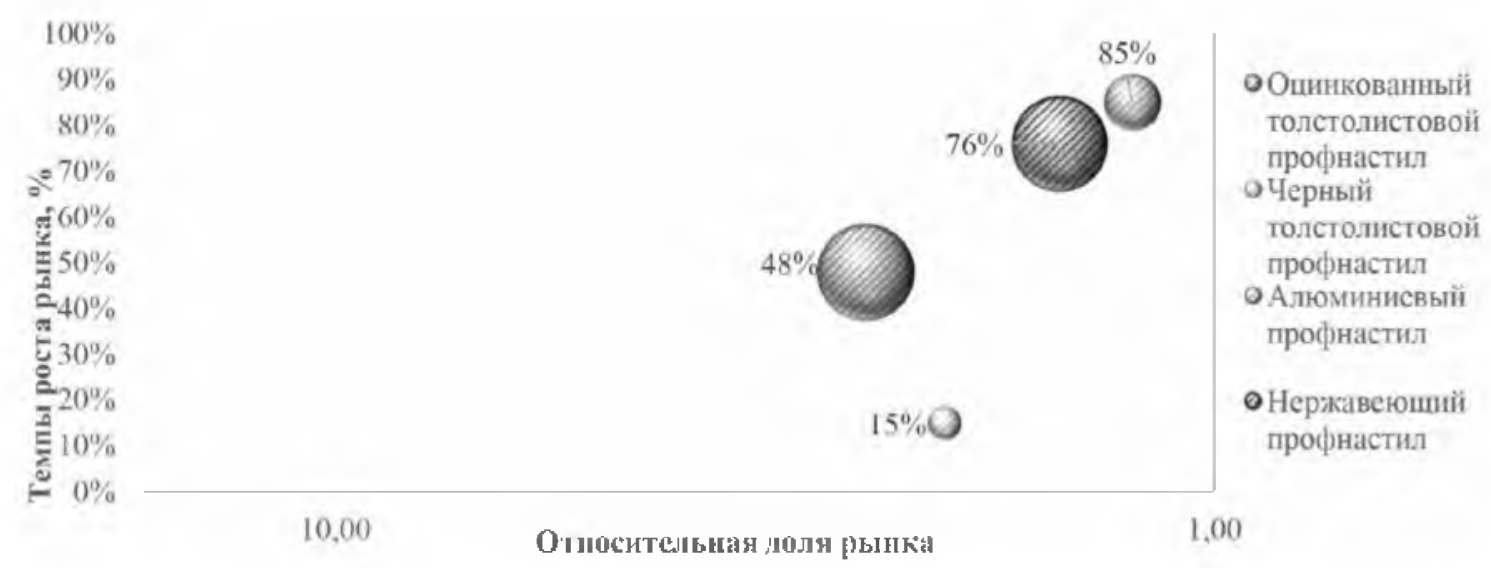

Рис. 4. Анализ продуктов ООО «ЗГП» в 2017 г. в соответствии с моделью ВСG*

*Рассчитано и составлено автором на основе материалов [7]

4. В рамках модели «Стратегия голубого океана» ООО «ЗГП» создает свободные от конкуренции рыночные пространства, что проявляется в освоении труднодоступных территорий и сотрудничестве с принципиально новыми целевыми аудиториями (в настоящий момент это не непосредственно заказчик, а проектные институты). Основывается такая стратегия на восьми основных принципах, приведенных на рис. 5.

Последний принцип позволяет компании посредством инноваций стабильно успешно функционировать на каждом этапе жизненного цикла предприятия. 


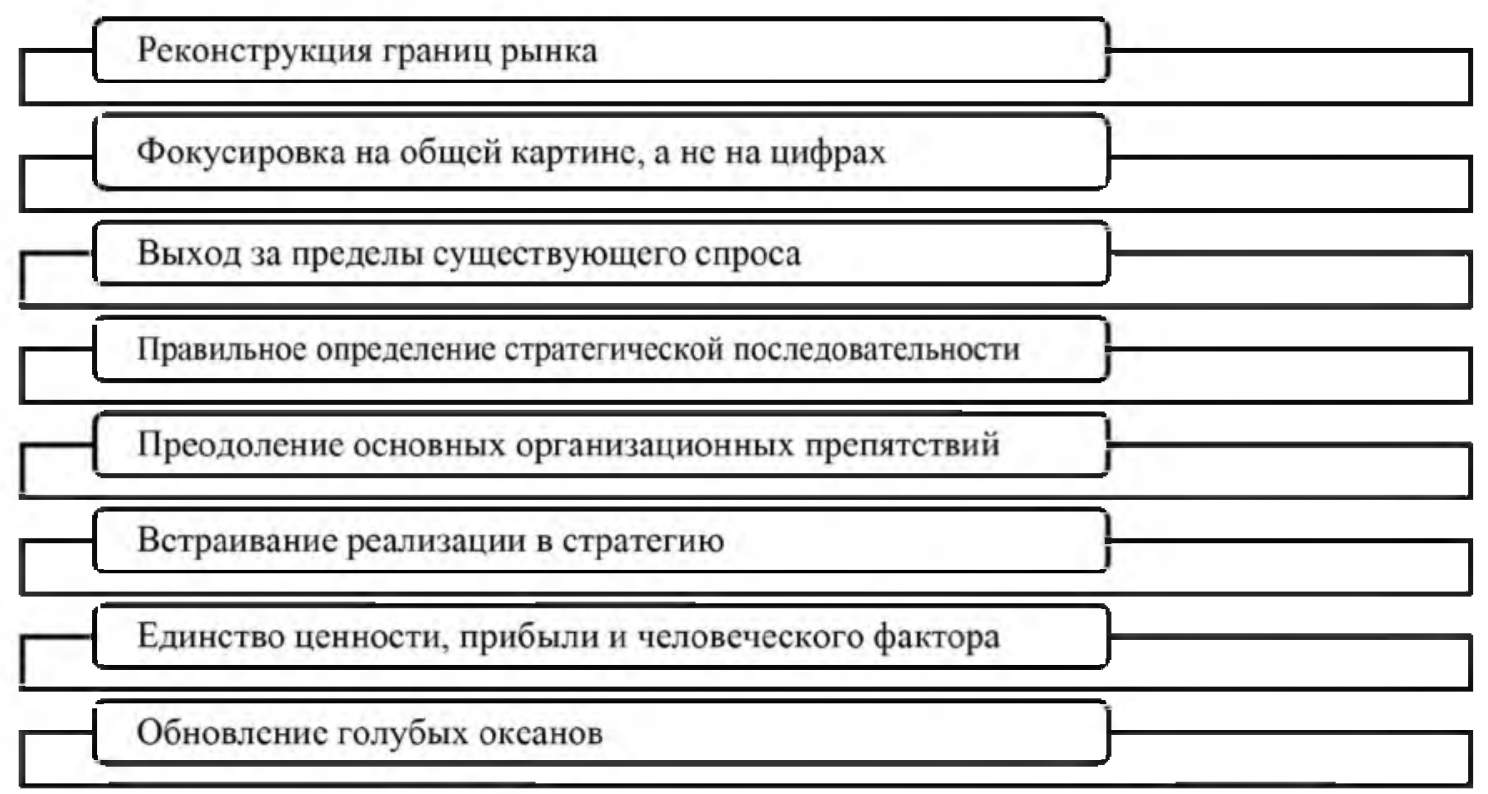

Рис. 5. Принципы стратегии голубого океана

5. На базе «Модели четырех действий» выстраивается новая кривая ценности на основе реконструкции компромисса между стремлением к понижению издержек и расширению дифференциации с учетом и соотнесение векторов отрасли, стратегии предприятия и выбранной бизнес-модели. На рис. 6 представлены ключевые вопросы, требующие ответа при следовании этой модели.

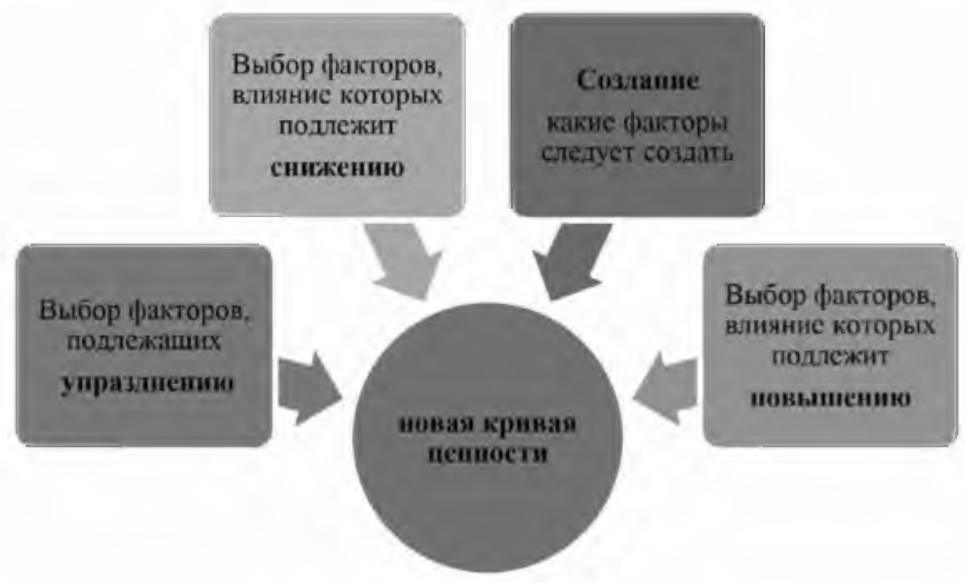

Рис. 6. Модель четьрех действий

На данное время в ООО «ЗГП» при разработке стратегии придерживается данной модели, в соответствии с которой определено, что:

- снизить необходимо затраты на сырье, затраты на производственные мощности;

- упразднить следует косвенный маркетинг;

- целесообразно создать в качестве нового продукта кровельные конструкции с меньшим весом и большей несущей способностью;

- повышению подлежит цена. 
6. Стратегическое целеполагание (рис. 7)

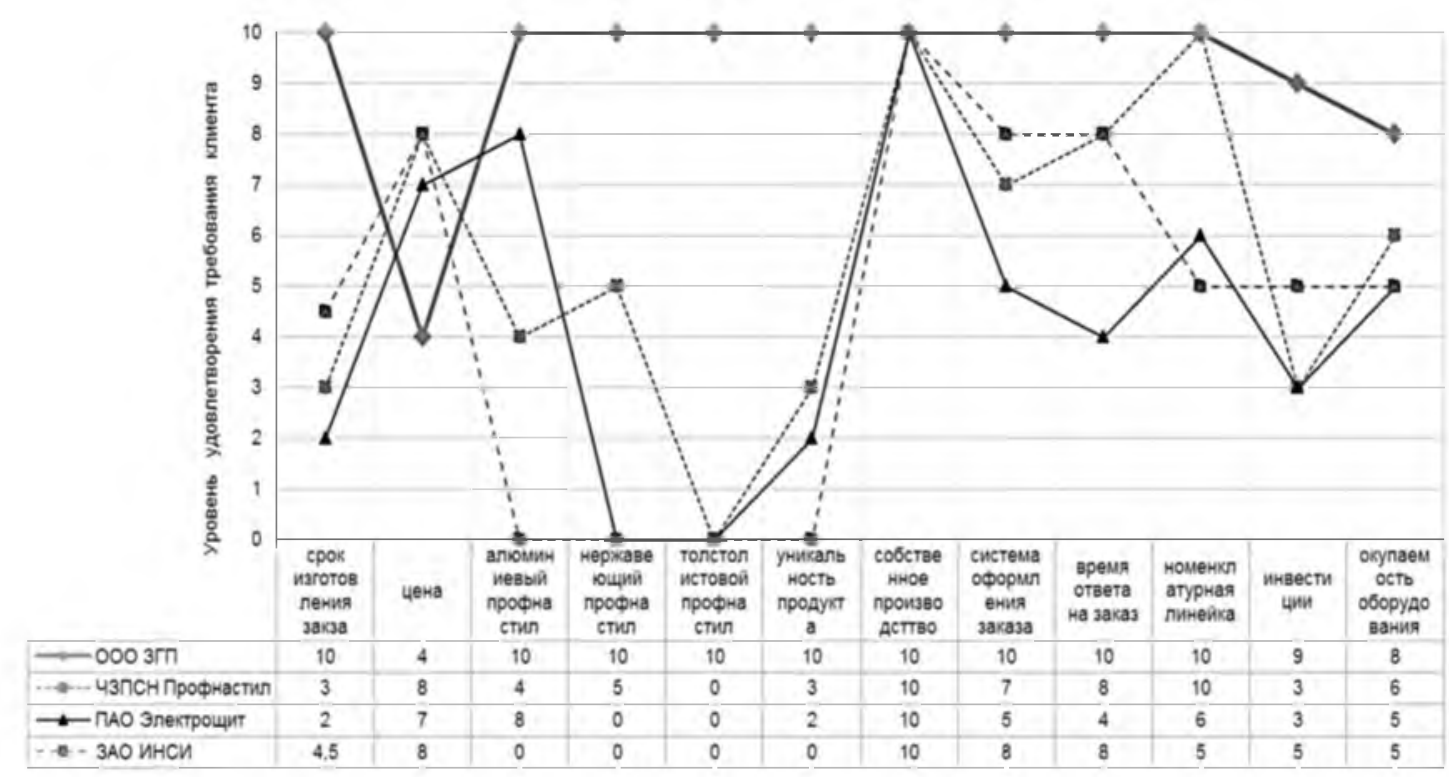

Рис. 7. Стратегическая канва ООО «ЗГП» в 2017 г.*

*Рассчитано и составлено автором на основе материалов [7]

В рамках этой модели выявлено, что стратегию 000 «ЗГП» целесообразно формулировать, учитывая следующие позиции:

a) финансовые цели: привлечение инвестиций и государственного финансирования; повышение экономической эффективности и стоимости бизнеса.

b) цели по удовлетворению клиентов: увеличение числа постоянных клиентов; привлечение новых клиентов.

c) цели по совершенствованию бизнес-процессов: совершенствование организационной структуры предприятия; совершенствование финансовой структуры предприятия, схемы технологического процесса и системы управленческого учета;

d) цели по развитию персонала: совершенствование механизмов стимулирования труда; повышение уровня квалификации персонала.

Заключение / Conclusion. Интеграционный анализ внешней среды и внутреннего потенциала предприятия дал возможность выявить, что реализацию рыночной стратегии ООО «Завод Гнутого Профиля) целесообразно осуществлять в рамках следующих целеустановок:

- цели: достижение максимизации прибыли и стоимости компании.

- показатели: объем производства, объем продаж, прибыль, рентабельность, ликвидность, финансовая устойчивость, стоимость предприятия, доходность инвестиций, заработная плата;

- целевые значения: по истечении первого года ожидается увидеть рост объема производства и продаж на $15 \%$, увеличение показателей рентабельности, ликвидности и финансовой устойчивости - на $10 \%$, рост рыночной стоимости предприятия - на $10 \%$. Со стороны собственников ожидается увеличение отдачи на вложенный капитал на $15 \%$, со стороны топ-менеджеров ожидается увеличение заработной платы на $10 \%$.

- инициативы: предполагается расширить ассортимент за счет введения инновационной продукции, увеличить объем производства и продаж в целом. Для этого предполагается привлечение венчурного капитала в комбинированный проект. В целях обеспечения 
инвестиционной привлекательности предприятия планируется уделить внимание детализации отчетности предприятия, ее большей прозрачности, для чего планируется организовать внедрение системы управленческого учета.

В дальнейшем автор планирует развивать эту тематику исследований в направлении поиска наиболее оптимальных путей соотнесения затрат и доходов при разработке рыночной стратегии предприятия.

\section{ЛИТЕРАТУРА И ИНТЕРНЕТ-РЕСУРСЫ}

1. Баженов О. В. Методика формирования прогнозных данных на основе результатов стратегического анализа (на примере предприятий медной промышленности) // Вестник УрФУ. Серия: Экономика и управление. 2015. Т. 14. № 3. С. 413-431.

2. Дивина Т. В., Онанко Н. А., Юрасов А. Б. Некоторые принципы построения антикризисных программ в контексте современной экономической ситуации // ФЭС: Финансы. Экономика. 2018. № 1. С. 17-22.

3. Калышенко В. Н., Сталькина У. М. Стратегический анализ маркетинговой среды предприятия // «Проблемы совершенствования организации производства и управления промышленными предприятиями»: межвузовский сборник научных трудов. Самара: СГЭУ, 2017. С. 108-113.

4. Скворцова К. В. Развитие методики оценки уровня экономической безопасности предприятия // Аудит и финансовый анализ. 2017. № 3-4. С. 654-657.

5. Тарелкин А. А. Алгоритм оценки инвестиционной привлекательности промышленных предприятий// Инновации и инвестиции. 2016. № 8. С. 22-27.

6. Арутюнова Д. В. Стратегический менеджмент: учебное пособие. Таганрог: Изд-во ТТИ ЮФУ, 2010. 122 с.

7. Финансово-экономическая отчетность и статистические данные ООО «Завод Гнутого Профиля» за 2014-2017 гг.

\section{REFERENCES AND INTERNET RESOURCES}

1. Bazhenov O. V. Metodika formirovaniya prognoznyh dannyh na osnove rezul'tatov strategicheskogo analiza (na primere predpriyatij mednoj promyshlennosti) (Methods of forming forecast data based on the results of a strategic analysis (on the example of the copper industry)) // Vestnik UrFU. Seriya: EHkonomika $\mathrm{i}$ upravlenie. 2015. T. 14. № 3. S. 413-431.

2. Divina T. V., Onanko N. A., YUrasov A. B. Nekotorye principy postroeniya antikrizisnyh programm v kontekste sovremennoj ehkonomicheskoj situacii (Some principles of building anti-crisis programs in the context of the current economic situation) // FEHS: Finansy. EHkonomika. 2018. № 1. S. 17-22.

3. Kalyshenko V. N., Stal'kina U. M. Strategicheskij analiz marketingovoj sredy predpriyatiya (Strategic analysis of the marketing environment of the enterprise) // Problemy sovershenstvovaniya organizacii proizvodstva i upravleniya promyshlennymi predpriyatiyami: mezhvuzovskij sbornik nauchnyh trudov. Samara: SGEHU, 2017. S. 108-113.

4. Skvorcova K. V. Razvitie metodiki ocenki urovnya ehkonomicheskoj bezopasnosti predpriyatiya (Development of methods for assessing the level of economic security of the enterprise) // Audit i finansovyj analiz. 2017. № 3-4. S. 654-657.

5. Tarelkin A. A. Algoritm ocenki investicionnoj privlekatel'nosti promyshlennyh predpriyatij (Algorithm for evaluating the investment attractiveness of industrial enterprises) // Innovacii i investicii. 2016. № 8. S. $22-27$.

6. Arutyunova D. V. Strategicheskij menedzhment: uchebnoe posobie (Strategic Management: Tutorial). Taganrog: Izd-vo TTI YUFU, 2010. $122 \mathrm{~s}$.

7. Finansovo-ehkonomicheskaya otchetnost' i statisticheskie dannye OOO «Zavod Gnutogo Profilya» za 20142017 gg. (Financial and economic reporting and statistical data LLC «Plant Bent Profile» for 2014-2017)

\section{СВЕДЕНИЯ ОБ АВТОРЕ}

Деперимидт Эллина Вадимовна, директор ООО «Завод Гнутого Профиля», г. Коркино, Россия. Е-таil: ellina09@mail.ru

\section{INFORMATION ABOUT AUTHOR}

Ellina Depershmidt, Director of LLC «Bent Profile Mill», Korkino, Russia. E-mail: ellina09@mail.ru 